\title{
Avaliando Resultados de Açóes de Segurança Pública
}

\section{Luís henrique Costa ferreira}

Polícia Civil do Estado da Bahia - Brasil<smiles>C=[W]#[W]</smiles>

\section{RESUMO}

É usual nas avaliações dos resultados das ações em segurança pública efetuar medições nos comportamentos de variáveis escolhidas como indicadoras para serem analisadas em termos de conglomerados representados por territórios. Os dados são discutidos em relação ao território para avaliar se houve, ou não, um aumento da frequência da variável estudada e os resultados são avaliados comparando os obtidos para diversos territórios. Apesar de fácil aplicação e interpretação, sempre observei com desconfiança esse sistema, pois não concordo em comparar territórios sem considerar as características sociais, históricas e econômicas dos mesmos. É imprescindível que as características individuais de cada território sejam levadas em conta. Este trabalho apresenta um modelo para a comparação das ações contra a violência desenvolvidas em diversos territórios que leva em conta o comportamento histórico da variável indicadora escolhida e possibilita avaliações de desempenho e proficiência consistentes.

A proposta do modelo desenvolvido é responder, considerando as características individuais dos territórios, qual deles apresentou um melhor resultado para variável criminal indicadora. Ou seja, indicar para médias e desvios padrões diferentes, em um mesmo intervalo de tempo, considerando uma determinada variável criminal, qual dos territórios apresentou um resultado relativamente melhor. E como todos os territórios podem ser classificados entre si.

Palavras-Chave: Crime. Série Temporal. Probabilidade. Análise.

\section{INTRODUÇÃ̃o}

É comum a variação da criminalidade em um território ser discutida a partir do valor de uma variável em termo absoluto, ou como é mais usual, em termo de uma taxa calculada considerando uma população padrão de 100.000 habitantes no território. Esse procedimento é utilizado no estudo da variação da criminalidade ao longo do tempo em um mesmo território, ou para comparar as frequências de eventos em 
territórios diversos. A avaliação desse índice (100.000 x "quantidade de crime"/"quantidade de habitantes") ${ }^{1}$.

O usual nessas avaliações é os comportamentos das variáveis escolhidas serem analisados em termos de conglomerados representados por territórios. Os estudos avaliam as mudanças nas variáveis em relação ao aumento ou diminuição da frequência dos eventos por elas representados em relação à medição anterior no próprio território. Os resultados são discutidos em relação ao território para avaliar se houve ou não um aumento na frequência da variável estudada e são avaliados comparando os diversos territórios para identificar qual deles propiciou uma maior redução da frequência da variável indicadora. Para essas situações é também usual antes converter o dado bruto para o escore populacional de $100.000^{2}$ habitantes no território com a finalidade de permitir compensar as diferenças populacionais nas comparações entre territórios ou, compensar as variações de população ocorridas na série temporal. Esse é o critério utilizado pela Organização das Nações Unidas - ONU nos estudos desenvolvidos pelo United Nations Office on Drugs an Crime (Escritório das Nações Unidas sobre Drogas e Crime (UNODC) , 2015) e por pesquisadores brasileiros a exemplo de Cláudio Beato, (BEATO, 2015).

Apesar de fácil aplicação e interpretação, sempre observei com desconfiança esse sistema, pois discordo em comparar territórios sem considerar as características sociais, históricas e econômicas dos mesmos. Comparar ações de segurança pública desenvolvidas em um território historicamente pacato com as desenvolvidas em outro território historicamente violento depende de algo mais do que identificar os comportamentos absolutos das variáveis indicadoras escolhidas. É imprescindível que as características individuais de cada território sejam levadas em conta. Este trabalho apresenta um modelo para a comparação dos resultados das ações de segurança pública desenvolvidas em diversos territórios que leva em conta o comportamento histórico da variável indicadora e possibilita avaliações de desempenho e proficiência consistentes.

Para tanto foi adotado que a variável criminal estudada ocorre no território obedecendo a uma distribuição de frequência que pode ser mo-

1 http://nacoesunidas.org/estudo-do-unodc-mostra-que-partes-das-americas-e-da-africa-registramos-maiores-indices-de-homicidios/

2 http://www.unodc.org/documents/lpo-brazil//Topics_crime/Dados/Taxa_homicidios_Nordeste_ PT.pdf 
delada como um Processo de Poisson. Primeiro foram utilizados dados gerados de maneira aleatória utilizando a ferramenta de Análise de Dados do aplicativo MS Excel. Foram geradas cinco séries de dados representando o comportamento da variável criminal em cinco territórios diferentes. Cada serie de dado foi gerada conforme o Processo de Poisson e foram utilizados quatro fatores $\lambda$ (lambda) diferentes, ou seja, duas séries foram geradas com mesmo $\lambda$ para proporcionar um referencial de controle. Em uma segunda fase o modelo foi testado com uso de dados sobre quantidade de ocorrências de homicídios em municípios brasileiros disponíveis no Mapa da Violência 2014, (WAISELFISZ, 2014).

A proposta é responder, considerando as características individuais dos territórios, qual deles apresentou um melhor resultado para variável criminal indicadora. Ou seja, indicar para médias e desvios padrões diferentes, em um mesmo intervalo de tempo, considerando uma determinada variável criminal, qual dos territórios apresentou um resultado relativamente melhor. E como todos os territórios podem ser classificados entre si.

\section{ReFERENCIAL Teórico}

É comum a variação da criminalidade em um território ser discutida a partir do valor de uma variável em termo absoluto, ou como é mais usual, em termo de uma taxa calculada considerando uma população padrão de 100.000 habitantes no território. Esse procedimento é utilizado no estudo da variação da criminalidade ao longo do tempo em um mesmo território, ou para comparar as frequências de eventos em territórios diversos. A avaliação desse índice (100.000 x "quantidade de crime"/"quantidade de habitantes") 3 . Para essas medições é usual antes converter o dado bruto para o escore populacional de $100.000^{4}$ habitantes no território com a finalidade de permitir compensar as diferenças populacionais nas comparações entre territórios ou, compensar as variações de população ocorridas na série temporal. Esse é o critério utilizado pela Organização das Nações Unidas - ONU nos estudos desenvolvidos pelo United Nations Office on Drugs an Crime (Escritório das Nações Unidas sobre Drogas e Crime (UNODC) , 2015) e por alguns pesquisadores brasileiros a exemplo de Cláudio Beato, (BEATO, 2015).

3 http://nacoesunidas.org/estudo-do-unodc-mostra-que-partes-das-americas-e-da-africa-registramos-maiores-indices-de-homicidios/

4 http://www.unodc.org/documents/lpo-brazil//Topics_crime/Dados/Taxa_homicidios_Nordeste_ PT.pdf 
Uma série temporal se caracteriza por conjunto de dados coletados sequencialmente ao longo do tempo e para os quais os valores das variáveis estão associados ao momento no tempo. Os dados relativos a quantidade mensal de registros de ocorrências delituosas coletados ao longo de vários anos é uma série temporal. Sob outro prisma, quando para os mesmos dados a associação ao tempo é desprezada temos uma situação de um corte transversal, (GUJARATI \& DAWN, 2011).

Larson explica que uma distribuição de probabilidade discreta lista cada valor possível que a variável aleatória pode assumir, junto com a sua probabilidade, (LARSON, 2010). O estudo da Teoria das Probabilidades possibilitou a identificação e a construção de modelos para explicar as diversas configurações das distribuições de probabilidades para variáveis discretas ou contínuas. A Distribuição de Poisson é um modelo probabilístico adequado para um grande número de fenômenos observáveis, (LOESCH, 2012). De modo básico a Distribuição de Poisson expressa a probabilidade de uma série de eventos independentes entre si ocorrer num certo período de tempo, área, ou volume. As condições limites preestabelecidas para as medições e coletas das amostras que irão subsidiar um estudo relacionado a um processo de Poisson são denominadas de área de oportunidade e podem ser um lapso de tempo, uma área, um volume etc. A Distribuição de Poisson tem sido utilizada para modelar diversos eventos observáveis de maneira aceitável, como por exemplo, o número de chamadas por minuto em uma central de telefônica; o número de chamadas por unidade de tempo em uma central de polícia, ou de bombeiros ou de um serviço de resgate; a ocorrência de certa espécie de animal em uma área de campo etc.

A Função de Probabilidade para uma Distribuição Poisson é:

$$
f(k ; \lambda)=\left(e^{-\lambda} \lambda^{k}\right) / k !
$$

Onde: e é a base do logaritmo natural, aproximadamente 2,$7182 ; \lambda$ é o número de esperado de sucessos e $\mathrm{k}=0,1,2, \ldots \infty$ é o número de sucessos (LAPPONI, 2005). Para uma Distribuição de Poisson ideal $\lambda=$ média, e média $=$ variância.

Quando não buscamos estimadores mais robustos é usual a utilização da média da amostra como estimador de lambda. 
A aproximação da Distribuição Poisson pela Normal é dada pela fórmula:

$$
Z=(x-\lambda) / \sqrt{ } \lambda
$$

A fórmula acima gera uma aproximação eficiente para valores de $\lambda>5$, (alguns autores pregam $\lambda>20$, outros ignoram esse detalhe) e que a distribuição de frequência seja próxima de uma simétrica com forma de sino. Para adaptar uma distribuição discreta à distribuição normal, que é contínua, é importante que se trabalhe com grandes amostras, em conformidade com o Teorema Central do Limite e que aos resultados seja aplicado um fator para a correção de continuidade. É importante observar que a aproximação de uma distribuição discreta para a distribuição normal irá gerar sempre uma aproximação da probabilidade procurada. O intervalo de confiança dessa operação será mais ou menos exigente em razão da finalidade do estudo. Para o nosso objetivo específico, pouco exigente em precisão, optamos por ignorar a necessidade de aplicação de fator para correção de continuidade.

"Um número isolado não conta uma história. Para compreender plenamente o significado de um número, é preciso analisar o processo que o criou. Para comparar um número com outro, eles precisam estar na mesma escala", (SCHMULLER, 2010, p. 111). A comparação entre valores decorrentes de origens diversas, para ter algum sentido, depende da aplicação de algum processo que venha a gerar valores padronizados. Quando se trabalha com distribuições normais, a padronização é obtida calculando para cada valor o correspondente Z-Escore, cuja fórmula é:

$$
z=(x-\mu) / \sigma
$$

A conversão para o correspondente Z-Escore transforma os valores para a escala comum da distribuição normal padrão. Vale observar que "a posição relativa de qualquer pontuação em uma distribuição depende muito do desvio padrão. As distâncias em unidades originais não significam muito sem que se saiba o desvio padrão", (RUMSEY, 2012, p. 151). A padronização de valores para Z-Escore passa utilizar como unidade de medida o desvio padrão da distribuição. O resultado será expresso em termos da quantidade de desvio padrão que o valor convertido esta em relação a um outro valor. Esse outro valor no geral é a média do conjunto de dados. 


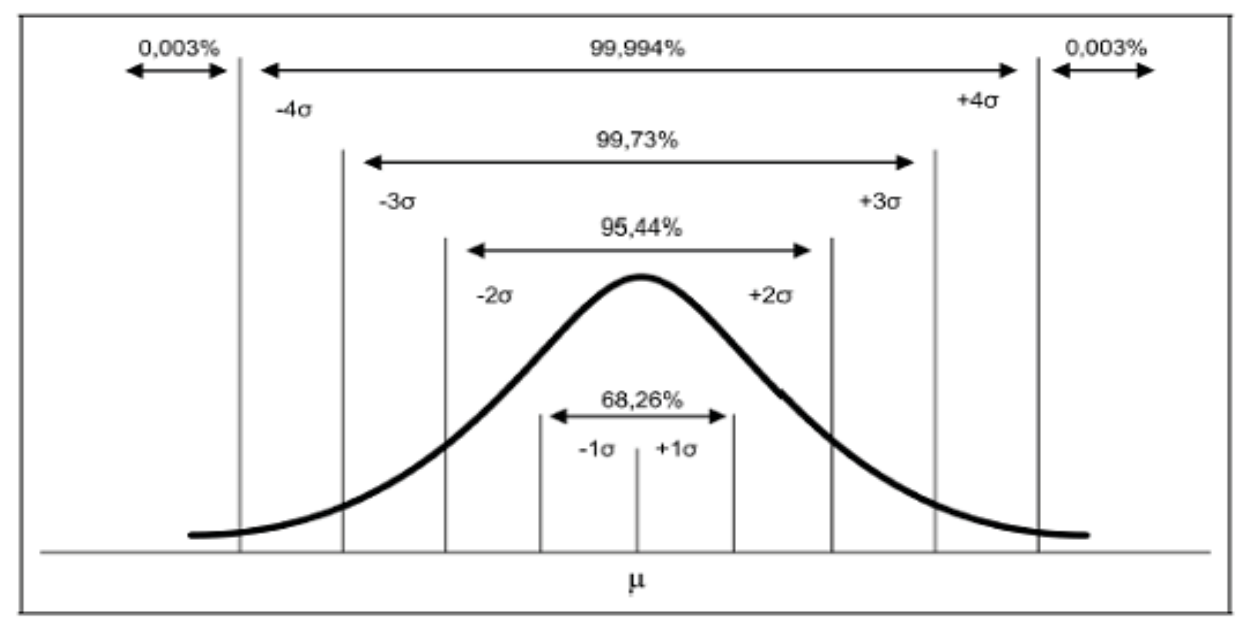

Gráfico 1 - Distribuição Normal

Quando comparamos valores provenientes de conjuntos de dados criminais, coletados e agrupados de territórios diferentes e em geral provenientes de séries temporais equivalentes, estamos comparando valores decorrentes de distribuições de frequência com características diversas. Nessas condições é fundamental que os valores sejam padronizados. Quanto mais distante da média esteja um valor padronizado menor é a probabilidade de que ele venha ocorrer, assim como a possibilidade de que ele venha a ocorrer ao acaso.

\section{Procedimentos Metodológicos}

$\mathrm{Na}$ primeira etapa deste trabalho não foram utilizados dados reais, mas sim material produzido por um gerador de números aleatórios dentro de restrições preestabelecidas, nessas circunstâncias não foram consideradas as limitações citadas para a aproximação da distribuição de Poisson para a Normal. Assim como desprezamos a necessidade de trabalhar com estatística robusta para a estimativa de fator $\lambda$, para o qual foi adotada a média da distribuição, também foi considerado desnecessário qualquer procedimento para a identificação e tratamento de outlier, vez que utilizamos "dados de laboratório". Cuidado especial foi dirigido aos tamanhos das amostras, para os quais foi adotado $\mathrm{n}=60$, simulando séries mensais equivalentes a cinco anos de observações. 
O procedimento obedeceu as seguintes etapas:

a) Geração das cinco séries, em conformidade com Processo de Poisson, com 60 dados (cada dado tomado como equivalente a um mês de medição da variável crime) utilizando a ferramenta de análise de dados do aplicativo MS Excel. Para valores de $\lambda$ foram adotados $1,2,3,4$ e 2 , sendo que o valor 2 foi adotado duas vezes para propiciar um referencial de controle, ou seja, para verificar se haveria discrepâncias entre as duas observações. Foram geradas as séries $\mathrm{A}$, B, C, D e E, simulando cinco territórios e colocadas em situação correspondente a sequência de $\lambda$ anterior.

\begin{tabular}{|c|c|}
\hline \multicolumn{2}{|c|}{$\mathbf{n = 6 0}$} \\
\hline Território /Série & $\lambda$ \\
\hline A & 1 \\
\hline B & 2 \\
\hline C & 3 \\
\hline D & 4 \\
\hline E & 2 \\
\hline Tabela 1 - Território e lambda correspondente
\end{tabular}

b) Foram calculadas as estatísticas descritivas básicas das séries

c) Para cada uma das séries A, B, C e, D foram gerados 4 valores aleatórios $(\mathrm{X})$, correspondentes a quantidade de ocorrência criminal a ser comparada, respeitando as propriedades específicas de cada uma das distribuições. Os valores de B foram utilizados em E para efeito de comparação conforme comentário anterior. Os valores foram gerados utilizando o MSEXCEL conforme já referido.

d) Os valores $(\mathrm{X})$ gerados no item c foram padronizados de acordo com a fórmula:

$$
Z=(x-\lambda) / \sqrt{ } \lambda
$$

e) Como o objetivo da medida é classificar os valores aleatórios (X) em termo de redução de criminalidade a escala adotada é decrescente, com o menor $(\mathrm{X})$ em melhor posição.

f) Os valores padronizados $Z(A), Z(B), Z(C), Z(D)$ e $Z(E)$ serão utilizados em conformidade com a escala decrescente para aferir o território com um resultado em segurança pública mais eficiente. 
g) Para facilitar a interpretação e a avaliação comparativa foi estipulada a Nota de Eficiência - NE, onde NE $=-1 \times Z$. Quanto maior o NE obtido pelo território melhor a classificação do resultado.

A seguir, distribuídos na Tabela 2, constam os valores gerados:

\begin{tabular}{|c|c|c|c|c|c|c|c|c|c|}
\hline \multirow{2}{*}{\multicolumn{2}{|c|}{$\begin{array}{c}\text { Território A } \\
\lambda=1\end{array}$}} & \multicolumn{2}{|c|}{ Território B } & \multicolumn{2}{|c|}{ Território C } & \multicolumn{2}{|c|}{ Território D } & \multicolumn{2}{|c|}{ Território E } \\
\hline & & & & & $=3$ & & $=4$ & & $=2$ \\
\hline MÊS & $\begin{array}{c}\text { Dado } \\
\text { Gerado }\end{array}$ & MÊS & $\begin{array}{l}\text { Dado } \\
\text { Gerado }\end{array}$ & MÊS & $\begin{array}{c}\text { Dado } \\
\text { Gerado }\end{array}$ & MÊS & $\begin{array}{l}\text { Dado } \\
\text { Gerado }\end{array}$ & MÊS & $\begin{array}{c}\text { Dado } \\
\text { Gerado }\end{array}$ \\
\hline mês 1 & 3 & mês 1 & 1 & mês 1 & 2 & mês 1 & 3 & mês 1 & 2 \\
\hline mês 2 & 1 & mês 2 & 1 & mês 2 & 4 & mês 2 & 6 & mês 2 & 3 \\
\hline mês 3 & 1 & mês 3 & 2 & mês 3 & 5 & mês 3 & 3 & mês 3 & 4 \\
\hline mês 4 & 1 & mês 4 & 2 & mês 4 & 1 & mês 4 & 4 & mês 4 & 3 \\
\hline mês 5 & 0 & mês 5 & 1 & mês 5 & 4 & mês 5 & 7 & mês 5 & 3 \\
\hline mês 6 & 1 & mês 6 & 2 & mês 6 & 5 & mês 6 & 6 & mês 6 & 1 \\
\hline mês 7 & 0 & mês 7 & 5 & mês 7 & 3 & mês 7 & 7 & mês 7 & 1 \\
\hline mês 8 & 2 & mês 8 & 0 & mês 8 & 4 & mês 8 & 5 & mês 8 & 1 \\
\hline mês 9 & 1 & mês 9 & 2 & mês 9 & 5 & mês 9 & 3 & mês 9 & 3 \\
\hline mês 10 & 2 & mês 10 & 1 & mês 10 & 3 & mês 10 & 3 & mês 10 & 3 \\
\hline mês 11 & 1 & mês 11 & 0 & mês 11 & 3 & mês 11 & 3 & mês 11 & 0 \\
\hline mês 12 & 3 & mês 12 & 2 & mês 12 & 4 & mês 12 & 4 & mês 12 & 1 \\
\hline mês 13 & 0 & mês 13 & 5 & mês 13 & 4 & mês 13 & 4 & mês 13 & 3 \\
\hline mês 14 & 4 & mês 14 & 2 & mês 14 & 1 & mês 14 & 1 & mês 14 & 3 \\
\hline mês 15 & 0 & mês 15 & 2 & mês 15 & 4 & mês 15 & 4 & mês 15 & 1 \\
\hline mês 16 & 0 & mês 16 & 3 & mês 16 & 4 & mês 16 & 4 & mês 16 & 4 \\
\hline mês 17 & 0 & mês 17 & 2 & mês 17 & 5 & mês 17 & 5 & mês 17 & 2 \\
\hline mês 18 & 2 & mês 18 & 0 & mês 18 & 4 & mês 18 & 4 & mês 18 & 2 \\
\hline mês 19 & 2 & mês 19 & 3 & mês 19 & 2 & mês 19 & 2 & mês 19 & 3 \\
\hline mês 20 & 0 & mês 20 & 4 & mês 20 & 2 & mês 20 & 2 & mês 20 & 2 \\
\hline mês 21 & 2 & mês 21 & 3 & mês 21 & 2 & mês 21 & 2 & mês 21 & 3 \\
\hline mês 22 & 1 & mês 22 & 0 & mês 22 & 0 & mês 22 & 0 & mês 22 & 3 \\
\hline mês 23 & 0 & mês 23 & 2 & mês 23 & 1 & mês 23 & 1 & mês 23 & 0 \\
\hline mês 24 & 2 & mês 24 & 2 & mês 24 & 6 & mês 24 & 6 & mês 24 & 1 \\
\hline mês 25 & 0 & mês 25 & 0 & mês 25 & 6 & mês 25 & 6 & mês 25 & 1 \\
\hline mês 26 & 1 & mês 26 & 2 & mês 26 & 4 & mês 26 & 4 & mês 26 & 1 \\
\hline mês 27 & 3 & mês 27 & 1 & mês 27 & 1 & mês 27 & 1 & mês 27 & 2 \\
\hline mês 28 & 1 & mês 28 & 2 & mês 28 & 4 & mês 28 & 4 & mês 28 & 3 \\
\hline mês 29 & 0 & mês 29 & 2 & mês 29 & 3 & mês 29 & 3 & mês 29 & 3 \\
\hline mês 30 & 1 & mês 30 & 1 & mês 30 & 2 & mês 30 & 2 & mês 30 & 0 \\
\hline mês 31 & 2 & mês 31 & 3 & mês 31 & 7 & mês 31 & 7 & mês 31 & 2 \\
\hline mês 32 & 0 & mês 32 & 2 & mês 32 & 3 & mês 32 & 3 & mês 32 & 2 \\
\hline
\end{tabular}




\begin{tabular}{|c|c|c|c|c|c|c|c|c|c|}
\hline \multirow{2}{*}{\multicolumn{2}{|c|}{$\begin{array}{c}\text { Território A } \\
\lambda=1\end{array}$}} & \multirow{2}{*}{\multicolumn{2}{|c|}{$\begin{array}{c}\text { Território B } \\
\lambda=2\end{array}$}} & \multirow{2}{*}{\multicolumn{2}{|c|}{$\begin{array}{c}\text { Território C } \\
\lambda=3\end{array}$}} & \multirow{2}{*}{\multicolumn{2}{|c|}{$\begin{array}{c}\text { Território D } \\
\lambda=4\end{array}$}} & \multirow{2}{*}{\multicolumn{2}{|c|}{$\begin{array}{c}\text { Território E } \\
\lambda=2\end{array}$}} \\
\hline & & & & & & & & & \\
\hline MÊS & $\begin{array}{c}\text { Dado } \\
\text { Gerado }\end{array}$ & MÊS & $\begin{array}{c}\text { Dado } \\
\text { Gerado }\end{array}$ & MÊS & $\begin{array}{c}\text { Dado } \\
\text { Gerado }\end{array}$ & MÊS & $\begin{array}{c}\text { Dado } \\
\text { Gerado }\end{array}$ & MÊS & $\begin{array}{c}\text { Dado } \\
\text { Gerado }\end{array}$ \\
\hline mês 33 & 1 & mês 33 & 2 & mês 33 & 4 & mês 33 & 4 & mês 33 & 2 \\
\hline mês 34 & 0 & mês 34 & 4 & mês 34 & 4 & mês 34 & 4 & mês 34 & 1 \\
\hline mês 35 & 1 & mês 35 & 4 & mês 35 & 9 & mês 35 & 9 & mês 35 & 3 \\
\hline mês 36 & 2 & mês 36 & 0 & mês 36 & 2 & mês 36 & 2 & mês 36 & 1 \\
\hline mês 37 & 1 & mês 37 & 2 & mês 37 & 1 & mês 37 & 1 & mês 37 & 1 \\
\hline mês 38 & 1 & mês 38 & 3 & mês 38 & 7 & mês 38 & 7 & mês 38 & 4 \\
\hline mês 39 & 3 & mês 39 & 2 & mês 39 & 2 & mês 39 & 2 & mês 39 & 3 \\
\hline mês 40 & 1 & mês 40 & 2 & mês 40 & 4 & mês 40 & 4 & mês 40 & 3 \\
\hline mês 41 & 1 & mês 41 & 1 & mês 41 & 2 & mês 41 & 2 & mês 41 & 0 \\
\hline mês 42 & 1 & mês 42 & 3 & mês 42 & 4 & mês 42 & 4 & mês 42 & 2 \\
\hline mês 43 & 0 & mês 43 & 2 & mês 43 & 3 & mês 43 & 3 & mês 43 & 1 \\
\hline mês 44 & 0 & mês 44 & 4 & mês 44 & 4 & mês 44 & 4 & mês 44 & 1 \\
\hline mês 45 & 0 & mês 45 & 3 & mês 45 & 5 & mês 45 & 5 & mês 45 & 2 \\
\hline mês 46 & 1 & mês 46 & 3 & mês 46 & 2 & mês 46 & 2 & mês 46 & 5 \\
\hline mês 47 & 2 & mês 47 & 2 & mês 47 & 3 & mês 47 & 3 & mês 47 & 2 \\
\hline mês 48 & 4 & mês 48 & 3 & mês 48 & 2 & mês 48 & 2 & mês 48 & 0 \\
\hline mês 49 & 1 & mês 49 & 3 & mês 49 & 2 & mês 49 & 2 & mês 49 & 1 \\
\hline mês 50 & 2 & mês 50 & 1 & mês 50 & 5 & mês 50 & 5 & mês 50 & 2 \\
\hline mês 51 & 0 & mês 51 & 1 & mês 51 & 6 & mês 51 & 6 & mês 51 & 3 \\
\hline mês 52 & 0 & mês 52 & 1 & mês 52 & 2 & mês 52 & 2 & mês 52 & 1 \\
\hline mês 53 & 1 & mês 53 & 2 & mês 53 & 2 & mês 53 & 2 & mês 53 & 1 \\
\hline mês 54 & 0 & mês 54 & 4 & mês 54 & 3 & mês 54 & 3 & mês 54 & 1 \\
\hline mês 55 & 0 & mês 55 & 1 & mês 55 & 3 & mês 55 & 3 & mês 55 & 1 \\
\hline mês 56 & 2 & mês 56 & 4 & mês 56 & 4 & mês 56 & 4 & mês 56 & 1 \\
\hline mês 57 & 1 & mês 57 & 0 & mês 57 & 2 & mês 57 & 2 & mês 57 & 1 \\
\hline mês 58 & 0 & mês 58 & 1 & mês 58 & 2 & mês 58 & 2 & mês 58 & 1 \\
\hline mês 59 & 3 & mês 59 & 5 & mês 59 & 5 & mês 59 & 5 & mês 59 & 4 \\
\hline mês 60 & 2 & mês 60 & 2 & mês 60 & 2 & mês 60 & 2 & mês 60 & 3 \\
\hline
\end{tabular}

Tabela 2 - Dados quantitativos

As estatísticas descritivas dos conjuntos de dados da Tabela 2 são (Tabela 3):

\begin{tabular}{|c|c|c|c|c|c|}
\hline \multicolumn{2}{|c|}{ Território A } & \multicolumn{2}{c|}{ Território B } & \multicolumn{2}{c|}{ Território C } \\
\hline Média & 1,133333 & Média & 2,083333 & Média & 3,4 \\
\hline Erro padrão & 0,139545 & Erro padrão & 0,168563 & Erro padrão & 0,221958 \\
\hline Mediana & 1 & Mediana & 2 & Mediana & 3 \\
\hline
\end{tabular}




\begin{tabular}{|c|c|c|c|c|c|}
\hline \multicolumn{2}{|c|}{ Território A } & \multicolumn{2}{|c|}{ Território B } & \multicolumn{2}{|c|}{ Território C } \\
\hline Modo & 1 & Modo & 2 & Modo & 2 \\
\hline $\begin{array}{l}\text { Desvio } \\
\text { padrão }\end{array}$ & 1,080908 & Desvio padrão & 1,305681 & $\begin{array}{l}\text { Desvio } \\
\text { padrão }\end{array}$ & 1,719282 \\
\hline $\begin{array}{c}\text { Variância da } \\
\text { amostra }\end{array}$ & 1,168362 & $\begin{array}{c}\text { Variância da } \\
\text { amostra }\end{array}$ & 1,704802 & $\begin{array}{c}\text { Variância da } \\
\text { amostra }\end{array}$ & 2,955932 \\
\hline Curtose & 0,078939 & Curtose & $-0,23069$ & Curtose & 0,84768 \\
\hline Assimetria & 0,809204 & Assimetria & 0,360919 & Assimetria & 0,693053 \\
\hline Intervalo & 4 & Intervalo & 5 & Intervalo & 9 \\
\hline \multicolumn{6}{|l|}{ Continua } \\
\hline Mínimo & 0 & Mínimo & 0 & Mínimo & 0 \\
\hline Máximo & 4 & Máximo & 5 & Máximo & 9 \\
\hline Soma & 68 & Soma & 125 & Soma & 204 \\
\hline Contagem & 60 & Contagem & 60 & Contagem & 60 \\
\hline
\end{tabular}

\begin{tabular}{|c|c|c|c|}
\hline \multicolumn{2}{|c|}{ Território D } & \multicolumn{2}{c|}{ Território E } \\
\hline Média & 3,583333 & Média & 1,95 \\
\hline Erro padrão & 0,236848 & Erro padrão & 0,152984 \\
\hline Mediana & 3 & Mediana & 2 \\
\hline Modo & 2 & Modo & 1 \\
\hline Desvio padrão & 1,834617 & Desvio padrão & 1,185005 \\
\hline Variância da amostra & 3,365819 & Variância da amostra & 1,404237 \\
\hline Curtose & 0,212833 & Curtose & $-0,61576$ \\
\hline Assimetria & 0,646173 & Assimetria & 0,289078 \\
\hline Intervalo & 9 & Intervalo & 5 \\
\hline Mínimo & 0 & Mínimo & 0 \\
\hline Máximo & 9 & Máximo & 5 \\
\hline Soma & 215 & Soma & 117 \\
\hline Contagem & 60 & Contagem & 60 \\
\hline
\end{tabular}

Tabela 3 - Estatísticas descritivas

Foram gerados 4 valores aleatórios $(\mathrm{X})$, correspondentes a quantidade de ocorrência criminal a ser comparada, respeitando as propriedades específicas de cada uma das distribuições. Os valores de B foram utilizados em E para efeito de comparação. As Notas de Eficiência - NE para cada serie sorteada foram calculadas considerando uma casa decimal. Os resultados estão a seguir na Tabela 4 


\begin{tabular}{|c|c|c|c|c|c|c|c|}
\hline $\begin{array}{c}\text { Resultados } \\
\text { Sorteados 1 }\end{array}$ & Sorteio & $\mathbf{Z}$ & $\mathbf{N E}$ & $\begin{array}{c}\text { Resultados } \\
\text { Sorteados 2 }\end{array}$ & Sorteio & $\mathbf{Z}$ & NE \\
\hline Território A & 0 & $-1,064581295$ & 1,1 & Território A & 3 & 1,753428015 & $-1,8$ \\
\hline Território B & 8 & 4,099186911 & $-4,1$ & Território B & 2 & $-0,057735027$ & 0,1 \\
\hline Território C & 4 & 0,325395687 & $-0,3$ & Território C & 3 & $-0,216930458$ & 0,2 \\
\hline Território D & 2 & $-0,836428361$ & 0,8 & Território D & 4 & 0,220112727 & $-0,2$ \\
\hline Território E & 8 & 4,332494988 & $-4,3$ & Território E & 2 & 0,035805744 & 0,0 \\
\hline Resultados & Sorteio & $\mathbf{Z}$ & $\mathbf{N E}$ & $\begin{array}{c}\text { Resultados } \\
\text { Sorteados 40 }\end{array}$ & Sorteio & $\mathbf{Z}$ & NE \\
\hline Sorteados 3 & 4 & 2,692764452 & $-2,7$ & Território A & 0 & $-1,064581295$ & 1,1 \\
\hline Território A & 4 & $-0,057735027$ & 0,1 & Território B & 2 & $-0,057735027$ & 0,1 \\
\hline Território B & 2 & 1,410047976 & $-1,4$ & Território C & 4 & 0,325395687 & $-0,3$ \\
\hline Território C & 6 & $-0,836428361$ & 0,8 & Território D & 6 & 1,276653814 & $-1,3$ \\
\hline Território D & 2 & 0,035805744 & 0,0 & Território E & 2 & 0,035805744 & 0,0 \\
\hline Território E & 2 & \multicolumn{7}{|c|}{ Tabela 4- Resultados } & & & \\
\hline
\end{tabular}

Os dados levam as seguintes conclusões, nas quais as maiores notas representam uma maior eficiência em relação a variável criminalidade medida, Tabela 5:

\begin{tabular}{|c|c|c|}
\hline Resultados Sorteados & \multicolumn{2}{|c|}{ Melhor Nota } \\
\hline $1^{\circ}$ & Território A & 1,1 \\
\hline $2^{\circ}$ & Território C & 0,2 \\
\hline $3^{\circ}$ & Território D & 0,8 \\
\hline $4^{\circ}$ & Território A & 1,1 \\
\hline
\end{tabular}

\begin{tabular}{|c|c|c|}
\hline Resultados Sorteados & Pior Nota & $-4,3$ \\
\hline $1^{\circ}$ & Território E & $-1,8$ \\
\hline $2^{\circ}$ & Território A & $-0,8$ \\
\hline $3^{\circ}$ & Território D & $-1,3$ \\
\hline $4^{\circ}$ & Território D & \\
\hline
\end{tabular}

Tabela 5 - Dados com Melhor e Pior Nota

O Território com maior nota representa aquele com melhor resultado na redução da variável crime estudada.

Para avaliação dos resultados finais, decorrentes de observações correspondentes a períodos, a proposta é que seja estabelecida uma Nota de Eficiência Final - NEF, calculada a partir da média das notas de eficiência - NE obtidas para o intervalo do período. Assim para um período de $\mathrm{n}$ meses, a nota final será calculada segundo a fórmula:

$$
N E F=\left(\sum_{(i=1)}^{n} N E / n\right)
$$


A seguir está a demonstração do cálculo da NEF para as séries sorteadas e identificadas com os algarismos $1^{\circ}, 2^{\circ}, 3^{\circ}$, e $4^{\circ}$. Os padróes de comparações considerados foram os valores correspondentes aos meses de 60 à $57 . \mathrm{Ou}$ seja, para um período de quatro meses está calculado a NEF em comparação com os quatros meses anteriores:

\begin{tabular}{|c|c|c|c|c|c|}
\hline \multicolumn{6}{|c|}{ NEF para o período de quatro meses } \\
\hline & $\begin{array}{c}\text { Soma do Valor } \\
\text { Sorteado }\end{array}$ & $\begin{array}{c}\text { Soma do Valor } \\
\text { Gerado }\end{array}$ & Variação \% & Variação & $\begin{array}{c}\text { NE Final - } \\
\text { NEF }\end{array}$ \\
\hline Território A & 7 & 6 & $16,67 \%$ & 1 & $-0,58$ \\
\hline Território B & 14 & 8 & $75,00 \%$ & 6 & $-0,98$ \\
\hline Território C & 17 & 11 & $54,55 \%$ & 6 & $-0,46$ \\
\hline Território D & 14 & 11 & $27,27 \%$ & 3 & 0,04 \\
\hline Território E & 14 & 9 & $55,56 \%$ & 5 & $-1,11$ \\
\hline
\end{tabular}

Tabela 6 - Cáuculo do NEF

Os resultados expostos estabelecem que as ações aplicadas do Território $\mathrm{D}$ foram mais eficazes para reduzir a variável criminal, pois lá ocorreu a obtenção de uma maior nota final - NEF quando comparamos com os resultados dos demais territórios. Isso para um período de avaliação do total de ocorrências de quatro meses em relação ao total de ocorrências dos quatro meses anteriores. Vale observar que em termos absolutos o Território $\mathrm{D}$ apresentou um incremento de três ocorrências e o Território $\mathrm{A}$ apresentou um incremento de apenas uma ocorrência. Em termos relativos o incremento do Território D foi de $27,27 \%$ e o do Território A foi de $16,67 \%$, as notas NEF respectivas foram 0,04 e - 0,58 . A maior eficiência do Território $\mathrm{D}$ com relação ao Território A é consequência de que, sob os parâmetros estabelecidos e considerando o comportamento das séries temporais da variável criminal, há uma maior probabilidade do Território A finalizar com um incremento de 1 , do que o Território $\mathrm{D}$ encerrar o período com um incremento de 3 ocorrências.

Os mesmos resultados serão obtidos aplicando a fórmula $\mathrm{Z}=(\mathrm{x}-$ $\lambda) / \sqrt{ } \lambda$ á média dos valores obtidos mês a mês para cada território. Assim a NEF será calculado com seguinte fórmula:

$$
N E F=\left(\left(\sum^{n}{ }^{n} x\right) / n-\lambda\right) / \sqrt{ } \lambda
$$


Onde x é o valor medido da variável crime em mês com o mês variando de 1 até $n$, sendo $n$ a quantidade de meses que compõe o intervalo.

Para testar o modelo foram selecionados entre os dados disponíveis no Mapa da Violência, (WAISELFISZ, 2014), quatorze Municípios dos Estados do Acre, Alagoas, Amazonas, Amapa, Bahia, Ceara, Rio de Janeiro e São Paulo. A seleção não foi aleatória, o critério buscou séries temporais com as distribuições de dados próximos uns dos outros, isso para permitir comparações.

O Mapa da Violência, (WAISELFISZ, 2014), contém informações de ocorrências de homicídios em todos os municípios da Federação, em séries anuais do ano 2008 até o ano 2012. As estatísticas, média e mediana, foram calculadas para cada uma das séries temporais considerando os valores dos anos 2008 até 2011 . O ano de 2012 foi utilizado para o cálculo das Notas de Eficiência - NE, que foram calculadas de duas maneiras utilizando $\lambda=$ média e $\lambda=$ mediana, por ser uma estatística mais robusta que a média. Na Tabela 7 , temos os municípios selecionados.

\begin{tabular}{|c|c|c|c|c|c|c|c|}
\hline \multirow{2}{*}{ Município } & \multirow{2}{*}{ UF } & \multirow{2}{*}{ Popul. 2012 } & \multicolumn{5}{|c|}{ Homicídios } \\
\cline { 4 - 8 } & & & 2008 & 2009 & 2010 & 2011 & 2012 \\
\hline Rio de Janeiro & RJ & 6.390 .290 & 1.910 & 1.952 & 1.764 & 1.467 & 1.372 \\
\hline Duque de Caxias & RJ & 867.067 & 606 & 582 & 576 & 519 & 472 \\
\hline Maceió & AL & 953.393 & 990 & 876 & 1.027 & 1.048 & 858 \\
\hline Salvador & BA & 2.710 .968 & 1.771 & 1.883 & 1.847 & 1.671 & 1.644 \\
\hline Juquitiba & SP & 29.081 & 18 & 20 & 34 & 24 & 15 \\
\hline Simões Filho & BA & 121.416 & 175 & 153 & 214 & 167 & 159 \\
\hline Tanque d'Arca & AL & 6.172 & 2 & 1 & 1 & 3 & 0 \\
\hline Marechal Thauma- & \multirow{2}{*}{ AC } & 15.123 & 1 & 2 & 1 & 2 & 0 \\
\hline turgo & & & & & & & \\
\hline São Brás & AL & 6.744 & 3 & 0 & 1 & 2 & 0 \\
\hline Cutias & AP & 4.910 & 2 & 1 & 1 & 1 & 0 \\
\hline Penaforte & CE & 8.483 & 0 & 3 & 2 & 0 & 0 \\
\hline Pindoba & AL & 2.857 & 0 & 1 & 1 & 0 & 0 \\
\hline Calçoene & AP & 9.343 & 4 & 1 & 2 & 1 & 1 \\
\hline Santa Luzia do Norte & AL & 6.967 & 1 & 6 & 5 & 1 & 2 \\
\hline Ferreira Gomes & AP & 6.141 & 3 & 5 & 1 & 4 & 2 \\
\hline Macaé & RJ & 217.951 & 114 & 81 & 109 & 90 & 92 \\
\hline Xapuri & AC & 16.639 & 2 & 0 & 1 & 4 & 1 \\
\hline
\end{tabular}




\begin{tabular}{|c|c|c|c|c|c|c|c|}
\hline \multirow{2}{*}{ Município } & \multirow{2}{*}{ UF } & \multirow{2}{*}{ Popul. 2012} & \multicolumn{5}{|c|}{ Homicídios } \\
\hline & & & 2008 & 2009 & 2010 & 2011 & 2012 \\
\hline $\begin{array}{c}\text { Campo Limpo } \\
\text { Paulista }\end{array}$ & SP & 75.637 & 8 & 14 & 20 & 9 & 11 \\
\hline Arapiraca & $\mathrm{AL}$ & 218.140 & 193 & 227 & 223 & 243 & 215 \\
\hline Porto Acre & $\mathrm{AC}$ & 15.534 & 0 & 1 & 5 & 4 & 2 \\
\hline Mâncio Lima & $\mathrm{AC}$ & 15.890 & 0 & 2 & 0 & 3 & 1 \\
\hline Votuporanga & SP & 86.059 & 27 & 8 & 7 & 13 & 13 \\
\hline Cosmópolis & SP & 61.013 & 11 & 6 & 9 & 12 & 9 \\
\hline Mazagão & $\mathrm{AP}$ & 17.794 & 5 & 4 & 3 & 1 & 3 \\
\hline Brasiléia & $\mathrm{AC}$ & 22.261 & 3 & 5 & 7 & 6 & 5 \\
\hline Feijó & $\mathrm{AC}$ & 32.560 & 6 & 6 & 7 & 10 & 7 \\
\hline Itapecerica da Serra & SP & 156.077 & 82 & 59 & 83 & 77 & 75 \\
\hline Rodrigues Alves & $\mathrm{AC}$ & 15.260 & 1 & 0 & 3 & 0 & 1 \\
\hline Roteiro & $\mathrm{AL}$ & 6.607 & 2 & 4 & 1 & 1 & 2 \\
\hline Umari & $\mathrm{CE}$ & 7.562 & 0 & 2 & 0 & 1 & 1 \\
\hline Apuí & $\mathrm{AM}$ & 18.633 & 11 & 4 & 4 & 2 & 6 \\
\hline Macapá & $\mathrm{AP}$ & 415.554 & 151 & 116 & 194 & 135 & 153 \\
\hline Acrelândia & $\mathrm{AC}$ & 13.011 & 0 & 1 & 4 & 1 & 2 \\
\hline Paraty & RJ & 38.740 & 22 & 29 & 16 & 18 & 24 \\
\hline Cabo Frio & RJ & 195.197 & 129 & 142 & 92 & 103 & 123 \\
\hline Cruzeiro do Sul & $\mathrm{AC}$ & 79.819 & 24 & 26 & 21 & 20 & 26 \\
\hline Senador Guiomard & $\mathrm{AC}$ & 20.588 & 2 & 1 & 3 & 2 & 3 \\
\hline Pracuúba & $\mathrm{AP}$ & 4.021 & 1 & 1 & 0 & 0 & 1 \\
\hline Plácido de Castro & $\mathrm{AC}$ & 17.587 & 3 & 0 & 4 & 4 & 4 \\
\hline Maués & $\mathrm{AM}$ & 54.079 & 1 & 3 & 14 & 13 & 10 \\
\hline Carapebus & RJ & 14.024 & 6 & 4 & 3 & 4 & 6 \\
\hline Laranjal do Jari & $\mathrm{AP}$ & 41.668 & 4 & 15 & 14 & 22 & 17 \\
\hline Lauro de Freitas & $\mathrm{BA}$ & 171.042 & 145 & 170 & 193 & 153 & 177 \\
\hline Urucará & $\mathrm{AM}$ & 16.902 & 0 & 1 & 4 & 2 & 3 \\
\hline $\begin{array}{c}\text { Campos dos Goyta- } \\
\text { cazes }\end{array}$ & RJ & 472.300 & 205 & 241 & 196 & 188 & 222 \\
\hline Itabuna & $\mathrm{BA}$ & 205.885 & 208 & 232 & 209 & 190 & 225 \\
\hline Coari & $\mathrm{AM}$ & 77.305 & 14 & 15 & 17 & 22 & 22 \\
\hline Eunápolis & $\mathrm{BA}$ & 102.628 & 88 & 118 & 93 & 62 & 102 \\
\hline São João do Jaguaribe & $\mathrm{CE}$ & 7.788 & 3 & 2 & 4 & 2 & 5 \\
\hline Oiapoque & $\mathrm{AP}$ & 21.661 & 6 & 11 & 4 & 5 & 10 \\
\hline Continua & & & & & & & \\
\hline Marechal Deodoro & $\mathrm{AL}$ & 47.504 & 35 & 34 & 33 & 48 & 46 \\
\hline
\end{tabular}




\begin{tabular}{|c|c|c|c|c|c|c|c|}
\hline \multirow{2}{*}{ Município } & \multirow{2}{*}{ UF } & \multirow{2}{*}{ Popul. 2012} & \multicolumn{5}{|c|}{ Homicídios } \\
\hline & & & 2008 & 2009 & 2010 & 2011 & 2012 \\
\hline Itaguaí & $\mathrm{RJ}$ & 113.182 & 61 & 31 & 58 & 50 & 60 \\
\hline Amapá & $\mathrm{AP}$ & 8.213 & 1 & 0 & 1 & 1 & 2 \\
\hline Itaubal & $\mathrm{AP}$ & 4.473 & 0 & 2 & 0 & 1 & 2 \\
\hline Tarumã & SP & 13.209 & 0 & 2 & 1 & 0 & 2 \\
\hline Maracaí & SP & 13.382 & 0 & 1 & 1 & 1 & 2 \\
\hline Porto Seguro & $\mathrm{BA}$ & 131.642 & 114 & 128 & 160 & 137 & 152 \\
\hline Barbalha & $\mathrm{CE}$ & 56.576 & 33 & 27 & 47 & 33 & 44 \\
\hline Lucélia & SP & 20.119 & 1 & 1 & 0 & 3 & 3 \\
\hline Potim & SP & 20.272 & 1 & 2 & 1 & 1 & 3 \\
\hline Novo Aripuanã & $\mathrm{AM}$ & 22.106 & 3 & 3 & 1 & 3 & 5 \\
\hline Teixeira de Freitas & $\mathrm{BA}$ & 143.001 & 73 & 101 & 121 & 131 & 123 \\
\hline Porto Grande & $\mathrm{AP}$ & 17.680 & 3 & 5 & 8 & 2 & 8 \\
\hline Santana & $\mathrm{AP}$ & 104.407 & 26 & 25 & 29 & 32 & 37 \\
\hline Jarinu & SP & 24.875 & 9 & 4 & 2 & 8 & 10 \\
\hline Manicoré & $\mathrm{AM}$ & 48.373 & 5 & 7 & 6 & 7 & 11 \\
\hline Porto de Pedras & $\mathrm{AL}$ & 8.156 & 0 & 0 & 1 & 1 & 2 \\
\hline Tartarugalzinho & $\mathrm{AP}$ & 13.385 & 3 & 3 & 1 & 1 & 5 \\
\hline Rio Branco & $\mathrm{AC}$ & 348.354 & 87 & 101 & 97 & 87 & 115 \\
\hline Pilar & $\mathrm{AL}$ & 33.623 & 36 & 22 & 28 & 35 & 43 \\
\hline Araçariguama & SP & 17.975 & 6 & 6 & 4 & 6 & 11 \\
\hline Tabuleiro do Norte & $\mathrm{CE}$ & 29.522 & 6 & 11 & 16 & 20 & 22 \\
\hline Rio Preto da Eva & $\mathrm{AM}$ & 26.948 & 6 & 2 & 7 & 4 & 10 \\
\hline $\begin{array}{c}\text { Santa Isabel do Rio } \\
\text { Negro }\end{array}$ & $\mathrm{AM}$ & 19.292 & 0 & 1 & 1 & 3 & 4 \\
\hline Autazes & $\mathrm{AM}$ & 33.312 & 0 & 1 & 4 & 4 & 6 \\
\hline Itaitinga & $\mathrm{CE}$ & 36.814 & 20 & 19 & 16 & 27 & 32 \\
\hline Tabatinga & $\mathrm{AM}$ & 54.440 & 13 & 23 & 17 & 16 & 28 \\
\hline Santo Anastácio & SP & 20.434 & 1 & 0 & 1 & 1 & 3 \\
\hline Japeri & RJ & 97.337 & 24 & 8 & 56 & 40 & 47 \\
\hline Miguel Pereira & $\mathrm{RJ}$ & 24.754 & 5 & 3 & 3 & 8 & 11 \\
\hline Rio das Ostras & RJ & 116.134 & 37 & 45 & 35 & 23 & 52 \\
\hline Saubara & $\mathrm{BA}$ & 11.354 & 1 & 9 & 1 & 3 & 9 \\
\hline Sena Madureira & $\mathrm{AC}$ & 39.366 & 4 & 1 & 6 & 10 & 12 \\
\hline Nova Iguaçu & RJ & 801.746 & 337 & 277 & 411 & 374 & 409 \\
\hline Itaparica & $\mathrm{BA}$ & 20.994 & 7 & 9 & 19 & 18 & 25 \\
\hline Coruripe & $\mathrm{AL}$ & 53.224 & 13 & 38 & 26 & 43 & 48 \\
\hline Satuba & $\mathrm{AL}$ & 15.020 & 2 & 12 & 5 & 14 & 18 \\
\hline
\end{tabular}




\begin{tabular}{|c|c|c|c|c|c|c|c|}
\hline \multirow{2}{*}{ Município } & \multirow{2}{*}{ UF } & \multirow{2}{*}{ Popul. 2012} & \multicolumn{5}{|c|}{ Homicídios } \\
\hline & & & 2008 & 2009 & 2010 & 2011 & 2012 \\
\hline Ilhéus & $\mathrm{BA}$ & 187.315 & 110 & 135 & 121 & 152 & 169 \\
\hline Murici & $\mathrm{AL}$ & 27.030 & 14 & 6 & 9 & 21 & 25 \\
\hline Rio Largo & $\mathrm{AL}$ & 68.952 & 53 & 29 & 39 & 75 & 74 \\
\hline Maracanaú & $\mathrm{CE}$ & 213.404 & 85 & 85 & 102 & 95 & 126 \\
\hline Aquiraz & $\mathrm{CE}$ & 74.465 & 39 & 26 & 37 & 30 & 54 \\
\hline Humaitá & $\mathrm{AM}$ & 45.954 & 4 & 5 & 4 & 8 & 14 \\
\hline Pojuca & $\mathrm{BA}$ & 34.106 & 9 & 15 & 10 & 20 & 28 \\
\hline Boa Viagem & $\mathrm{CE}$ & 52.829 & 16 & 11 & 14 & 15 & 29 \\
\hline Benjamin Constant & $\mathrm{AM}$ & 34.950 & 3 & 0 & 1 & 4 & 8 \\
\hline Matão & SP & 77.546 & 5 & 2 & 5 & 3 & 12 \\
\hline Mangaratiba & RJ & 38.201 & 17 & 14 & 18 & 12 & 33 \\
\hline Barcelos & $\mathrm{AM}$ & 25.948 & 4 & 3 & 3 & 3 & 12 \\
\hline Epitaciolândia & $\mathrm{AC}$ & 15.679 & 0 & 0 & 2 & 1 & 5 \\
\hline Camaçari & BA & 255.238 & 138 & 124 & 144 & 187 & 209 \\
\hline $\begin{array}{c}\text { Pedra Branca do } \\
\text { Amapari }\end{array}$ & $\mathrm{AP}$ & 11.794 & 2 & 0 & 0 & 2 & 6 \\
\hline São Paulo & SP & 11.376 .685 & 1.622 & 1.681 & 1.535 & 1.347 & 1.752 \\
\hline Eusébio & $\mathrm{CE}$ & 47.993 & 17 & 16 & 23 & 14 & 43 \\
\hline Horizonte & $\mathrm{CE}$ & 58.418 & 12 & 15 & 17 & 23 & 42 \\
\hline Pacajus & $\mathrm{CE}$ & 64.521 & 12 & 18 & 15 & 9 & 37 \\
\hline Ibirapitanga & $\mathrm{BA}$ & 22.683 & 3 & 10 & 9 & 12 & 28 \\
\hline Juazeiro do Norte & $\mathrm{CE}$ & 255.648 & 97 & 72 & 64 & 82 & 143 \\
\hline Mata de São João & BA & 41.527 & 15 & 17 & 24 & 42 & 62 \\
\hline Manaus & $\mathrm{AM}$ & 1.861 .838 & 656 & 755 & 843 & 1.029 & 1.052 \\
\hline Fortaleza & $\mathrm{CE}$ & 2.500 .194 & 888 & 902 & 1.268 & 1.337 & 1.920 \\
\hline
\end{tabular}

Tabela 7 - Municípios Selecionados

As estatísticas, média e mediana, das séries temporais da Tabela 7 , assim como as Notas de Eficiência - NE, calculadas utilizando a média e a mediana estão dispostas na Tabela 8, classificadas pela NE(média) a Nota de Eficiência calculada utilizando $\lambda=$ média.

\begin{tabular}{|c|c|c|c|c|c|}
\hline \multirow{2}{*}{ Município } & \multirow{2}{*}{ UF } & \multicolumn{2}{|c|}{ Estatísticas } & \multicolumn{2}{|c|}{ Notas } \\
\cline { 3 - 6 } & & Mediana & Média & $\begin{array}{c}\text { NE } \\
\text { (mediana) }\end{array}$ & $\begin{array}{c}\text { NE } \\
\text { (média) }\end{array}$ \\
\hline Rio de Janeiro & RJ & $1.837,00$ & $1.773,25$ & 10,85 & 9,53 \\
\hline Duque de Caxias & RJ & 579,00 & 570,75 & 4,45 & 4,13 \\
\hline
\end{tabular}




\begin{tabular}{|c|c|c|c|c|c|}
\hline \multirow[b]{2}{*}{ Município } & \multirow[b]{2}{*}{ UF } & \multicolumn{2}{|c|}{ Estatísticas } & \multicolumn{2}{|c|}{ Notas } \\
\hline & & Mediana & Média & $\begin{array}{c}\mathrm{NE} \\
\text { (mediana) }\end{array}$ & $\begin{array}{c}\mathrm{NE} \\
\text { (média) }\end{array}$ \\
\hline Maceió & $\mathrm{AL}$ & $1.008,50$ & 985,25 & 4,74 & 4,05 \\
\hline Salvador & BA & $1.809,00$ & $1.793,00$ & 3,88 & 3,52 \\
\hline Juquitiba & SP & 22,00 & 24,00 & 1,49 & 1,84 \\
\hline Simões Filho & BA & 171,00 & 177,25 & 0,92 & 1,37 \\
\hline Tanque d'Arca & $\mathrm{AL}$ & 1,50 & 1,75 & 1,22 & 1,32 \\
\hline Marechal Thaumaturgo & $\mathrm{AC}$ & 1,50 & 1,50 & 1,22 & 1,22 \\
\hline São Brás & $\mathrm{AL}$ & 1,50 & 1,50 & 1,22 & 1,22 \\
\hline Cutias & $\mathrm{AP}$ & 1,00 & 1,25 & 1,00 & 1,12 \\
\hline Penaforte & $\mathrm{CE}$ & 1,00 & 1,25 & 1,00 & 1,12 \\
\hline Pindoba & $\mathrm{AL}$ & 0,50 & 0,50 & 0,71 & 0,71 \\
\hline Calçoene & $\mathrm{AP}$ & 1,50 & 2,00 & 0,41 & 0,71 \\
\hline Santa Luzia do Norte & $\mathrm{AL}$ & 3,00 & 3,25 & 0,58 & 0,69 \\
\hline Ferreira Gomes & AP & 3,50 & 3,25 & 0,80 & 0,69 \\
\hline Macaé & $\mathrm{RJ}$ & 99,50 & 98,50 & 0,75 & 0,65 \\
\hline Armação dos Búzios & $\mathrm{RJ}$ & 18,00 & 18,50 & 0,47 & 0,58 \\
\hline Xapuri & $\mathrm{AC}$ & 1,50 & 1,75 & 0,41 & 0,57 \\
\hline Campo Limpo Paulista & SP & 11,50 & 12,75 & 0,15 & 0,49 \\
\hline Arapiraca & $\mathrm{AL}$ & 225,00 & 221,50 & 0,67 & 0,44 \\
\hline Porto Acre & $\mathrm{AC}$ & 2,50 & 2,50 & 0,32 & 0,32 \\
\hline Mâncio Lima & $\mathrm{AC}$ & 1,00 & 1,25 & 0,00 & 0,22 \\
\hline Votuporanga & SP & 10,50 & 13,75 & $-0,77$ & 0,20 \\
\hline Cosmópolis & SP & 10,00 & 9,50 & 0,32 & 0,16 \\
\hline Mazagão & $\mathrm{AP}$ & 3,50 & 3,25 & 0,27 & 0,14 \\
\hline Brasiléia & $\mathrm{AC}$ & 5,50 & 5,25 & 0,21 & 0,11 \\
\hline Feijó & $\mathrm{AC}$ & 6,50 & 7,25 & $-0,20$ & 0,09 \\
\hline Itapecerica da Serra & SP & 79,50 & 75,25 & 0,50 & 0,03 \\
\hline Rodrigues Alves & $\mathrm{AC}$ & 0,50 & 1,00 & $-0,71$ & 0,00 \\
\hline Roteiro & $\mathrm{AL}$ & 1,50 & 2,00 & $-0,41$ & 0,00 \\
\hline Umari & $\mathrm{CE}$ & 0,50 & 0,75 & $-0,71$ & $-0,29$ \\
\hline Apuí & $\mathrm{AM}$ & 4,00 & 5,25 & $-1,00$ & $-0,33$ \\
\hline Macapá & $\mathrm{AP}$ & 143,00 & 149,00 & $-0,84$ & $-0,33$ \\
\hline Acrelândia & $\mathrm{AC}$ & 1,00 & 1,50 & $-1,00$ & $-0,41$ \\
\hline Paraty & $\mathrm{RJ}$ & 20,00 & 21,25 & $-0,89$ & $-0,60$ \\
\hline Cabo Frio & $\mathrm{RJ}$ & 116,00 & 116,50 & $-0,65$ & $-0,60$ \\
\hline Cruzeiro do Sul & $\mathrm{AC}$ & 22,50 & 22,75 & $-0,74$ & $-0,68$ \\
\hline Senador Guiomard & $\mathrm{AC}$ & 2,00 & 2,00 & $-0,71$ & $-0,71$ \\
\hline
\end{tabular}




\begin{tabular}{|c|c|c|c|c|c|}
\hline \multirow[b]{2}{*}{ Município } & \multirow[b]{2}{*}{ UF } & \multicolumn{2}{|c|}{ Estatísticas } & \multicolumn{2}{|c|}{ Notas } \\
\hline & & Mediana & Média & $\begin{array}{c}\mathrm{NE} \\
\text { (mediana) }\end{array}$ & $\begin{array}{c}\mathrm{NE} \\
\text { (média) }\end{array}$ \\
\hline Pracuúba & $\mathrm{AP}$ & 0,50 & 0,50 & $-0,71$ & $-0,71$ \\
\hline Plácido de Castro & $\mathrm{AC}$ & 3,50 & 2,75 & $-0,27$ & $-0,75$ \\
\hline Maués & $\mathrm{AM}$ & 8,00 & 7,75 & $-0,71$ & $-0,81$ \\
\hline Carapebus & RJ & 4,00 & 4,25 & $-1,00$ & $-0,85$ \\
\hline Laranjal do Jari & $\mathrm{AP}$ & 14,50 & 13,75 & $-0,66$ & $-0,88$ \\
\hline Lauro de Freitas & BA & 161,50 & 165,25 & $-1,22$ & $-0,91$ \\
\hline Urucará & $\mathrm{AM}$ & 1,50 & 1,75 & $-1,22$ & $-0,94$ \\
\hline Campos dos Goytacazes & RJ & 200,50 & 207,50 & $-1,52$ & $-1,01$ \\
\hline Itabuna & BA & 208,50 & 209,75 & $-1,14$ & $-1,05$ \\
\hline Coari & $\mathrm{AM}$ & 16,00 & 17,00 & $-1,50$ & $-1,21$ \\
\hline Eunápolis & BA & 90,50 & 90,25 & $-1,21$ & $-1,24$ \\
\hline São João do Jaguaribe & $\mathrm{CE}$ & 2,50 & 2,75 & $-1,58$ & $-1,36$ \\
\hline Oiapoque & $\mathrm{AP}$ & 5,50 & 6,50 & $-1,92$ & $-1,37$ \\
\hline Marechal Deodoro & $\mathrm{AL}$ & 34,50 & 37,50 & $-1,96$ & $-1,39$ \\
\hline Itaguaí & $\mathrm{RJ}$ & 54,00 & 50,00 & $-0,82$ & $-1,41$ \\
\hline Amapá & $\mathrm{AP}$ & 1,00 & 0,75 & $-1,00$ & $-1,44$ \\
\hline Itaubal & $\mathrm{AP}$ & 0,50 & 0,75 & $-2,12$ & $-1,44$ \\
\hline Tarumã & SP & 0,50 & 0,75 & $-2,12$ & $-1,44$ \\
\hline Maracaí & SP & 1,00 & 0,75 & $-1,00$ & $-1,44$ \\
\hline Porto Seguro & BA & 132,50 & 134,75 & $-1,69$ & $-1,49$ \\
\hline Barbalha & $\mathrm{CE}$ & 33,00 & 35,00 & $-1,91$ & $-1,52$ \\
\hline Lucélia & SP & 1,00 & 1,25 & $-2,00$ & $-1,57$ \\
\hline Potim & SP & 1,00 & 1,25 & $-2,00$ & $-1,57$ \\
\hline Novo Aripuanã & $\mathrm{AM}$ & 3,00 & 2,50 & $-1,15$ & $-1,58$ \\
\hline Teixeira de Freitas & BA & 111,00 & 106,50 & $-1,14$ & $-1,60$ \\
\hline Porto Grande & $\mathrm{AP}$ & 4,00 & 4,50 & $-2,00$ & $-1,65$ \\
\hline Santana & $\mathrm{AP}$ & 27,50 & 28,00 & $-1,81$ & $-1,70$ \\
\hline Jarinu & SP & 6,00 & 5,75 & $-1,63$ & $-1,77$ \\
\hline Manicoré & $\mathrm{AM}$ & 6,50 & 6,25 & $-1,77$ & $-1,90$ \\
\hline Porto de Pedras & $\mathrm{AL}$ & 0,50 & 0,50 & $-2,12$ & $-2,12$ \\
\hline Tartarugalzinho & $\mathrm{AP}$ & 2,00 & 2,00 & $-2,12$ & $-2,12$ \\
\hline Rio Branco & $\mathrm{AC}$ & 92,00 & 93,00 & $-2,40$ & $-2,28$ \\
\hline Pilar & $\mathrm{AL}$ & 31,50 & 30,25 & $-2,05$ & $-2,32$ \\
\hline Araçariguama & SP & 6,00 & 5,50 & $-2,04$ & $-2,35$ \\
\hline Tabuleiro do Norte & $\mathrm{CE}$ & 13,50 & 13,25 & $-2,31$ & $-2,40$ \\
\hline Rio Preto da Eva & $\mathrm{AM}$ & 5,00 & 4,75 & $-2,24$ & $-2,41$ \\
\hline
\end{tabular}




\begin{tabular}{|c|c|c|c|c|c|}
\hline \multirow[b]{2}{*}{ Município } & \multirow[b]{2}{*}{ UF } & \multicolumn{2}{|c|}{ Estatísticas } & \multicolumn{2}{|c|}{ Notas } \\
\hline & & Mediana & Média & $\begin{array}{c}\mathrm{NE} \\
\text { (mediana) }\end{array}$ & $\begin{array}{c}\mathrm{NE} \\
\text { (média) }\end{array}$ \\
\hline $\begin{array}{l}\text { Santa Isabel do Rio } \\
\text { Negro }\end{array}$ & $\mathrm{AM}$ & 1,00 & 1,25 & $-3,00$ & $-2,46$ \\
\hline Autazes & $\mathrm{AM}$ & 2,50 & 2,25 & $-2,21$ & $-2,50$ \\
\hline Itaitinga & $\mathrm{CE}$ & 19,50 & 20,50 & $-2,83$ & $-2,54$ \\
\hline Tabatinga & $\mathrm{AM}$ & 16,50 & 17,25 & $-2,83$ & $-2,59$ \\
\hline Santo Anastácio & SP & 1,00 & 0,75 & $-2,00$ & $-2,60$ \\
\hline Japeri & RJ & 32,00 & 32,00 & $-2,65$ & $-2,65$ \\
\hline Miguel Pereira & $\mathrm{RJ}$ & 4,00 & 4,75 & $-3,50$ & $-2,87$ \\
\hline Rio das Ostras & $\mathrm{RJ}$ & 36,00 & 35,00 & $-2,67$ & $-2,87$ \\
\hline Saubara & BA & 2,00 & 3,50 & $-4,95$ & $-2,94$ \\
\hline Sena Madureira & AC & 5,00 & 5,25 & $-3,13$ & $-2,95$ \\
\hline Nova Iguaçu & RJ & 355,50 & 349,75 & $-2,84$ & $-3,17$ \\
\hline Itaparica & $\mathrm{BA}$ & 13,50 & 13,25 & $-3,13$ & $-3,23$ \\
\hline Coruripe & $\mathrm{AL}$ & 32,00 & 30,00 & $-2,83$ & $-3,29$ \\
\hline Satuba & $\overline{\mathrm{AL}}$ & 8,50 & 8,25 & $-3,26$ & $-3,39$ \\
\hline Ilhéus & $\mathrm{BA}$ & 128,00 & 129,50 & $-3,62$ & $-3,47$ \\
\hline Murici & $\mathrm{AL}$ & 11,50 & 12,50 & $-3,98$ & $-3,54$ \\
\hline Rio Largo & $\mathrm{AL}$ & 46,00 & 49,00 & $-4,13$ & $-3,57$ \\
\hline Maracanaú & $\mathrm{CE}$ & 90,00 & 91,75 & $-3,79$ & $-3,58$ \\
\hline Aquiraz & $\mathrm{CE}$ & 33,50 & 33,00 & $-3,54$ & $-3,66$ \\
\hline Humaitá & $\mathrm{AM}$ & 4,50 & 5,25 & $-4,48$ & $-3,82$ \\
\hline Pojuca & $\mathrm{BA}$ & 12,50 & 13,50 & $-4,38$ & $-3,95$ \\
\hline Boa Viagem & $\mathrm{CE}$ & 14,50 & 14,00 & $-3,81$ & $-4,01$ \\
\hline Benjamin Constant & $\mathrm{AM}$ & 2,00 & 2,00 & $-4,24$ & $-4,24$ \\
\hline Matão & SP & 4,00 & 3,75 & $-4,00$ & $-4,26$ \\
\hline Mangaratiba & $\mathrm{RJ}$ & 15,50 & 15,25 & $-4,45$ & $-4,55$ \\
\hline Barcelos & $\mathrm{AM}$ & 3,00 & 3,25 & $-5,20$ & $-4,85$ \\
\hline Epitaciolândia & $\mathrm{AC}$ & 0,50 & 0,75 & $-6,36$ & $-4,91$ \\
\hline Camaçari & $\mathrm{BA}$ & 141,00 & 148,25 & $-5,73$ & $-4,99$ \\
\hline $\begin{array}{c}\text { Pedra Branca do } \\
\text { Amapari }\end{array}$ & $\mathrm{AP}$ & 1,00 & 1,00 & $-5,00$ & $-5,00$ \\
\hline São Paulo & SP & $1.578,50$ & $1.546,25$ & $-4,37$ & $-5,23$ \\
\hline Eusébio & $\mathrm{CE}$ & 16,50 & 17,50 & $-6,52$ & $-6,10$ \\
\hline Horizonte & $\mathrm{CE}$ & 16,00 & 16,75 & $-6,50$ & $-6,17$ \\
\hline Pacajus & $\mathrm{CE}$ & 13,50 & 13,50 & $-6,40$ & $-6,40$ \\
\hline Ibirapitanga & $\mathrm{BA}$ & 9,50 & 8,50 & $-6,00$ & $-6,69$ \\
\hline
\end{tabular}




\begin{tabular}{|c|c|c|c|c|c|}
\hline \multirow{2}{*}{ Município } & \multirow{2}{*}{ UF } & \multicolumn{2}{|c|}{ Estatísticas } & \multicolumn{2}{c|}{ Notas } \\
\cline { 3 - 6 } & & Mediana & Média & $\begin{array}{c}\text { NE } \\
\text { (mediana) }\end{array}$ & $\begin{array}{c}\text { NE } \\
\text { (média) }\end{array}$ \\
\hline Juazeiro do Norte & CE & 77,00 & 78,75 & $-7,52$ & $-7,24$ \\
\hline Mata de São João & BA & 20,50 & 24,50 & $-9,17$ & $-7,58$ \\
\hline Manaus & AM & 799,00 & 820,75 & $-8,95$ & $-8,07$ \\
\hline Fortaleza & CE & $1.085,00$ & $1.098,75$ & $-25,35$ & $-24,78$ \\
\hline \multicolumn{4}{|c|}{ Tabela 8 - Estatísticas, média, mediana e Notas de Eficiência - NE } \\
\hline
\end{tabular}

A Tabela 8 deixa evidente que a redução do número de homicídios no Município de Rio de Janeiro foi um resultado mais distante da média da série histórica do que a redução do mesmo delito para o Município de Itapecerica da Serra. A NE(média) calculada para o Município de Itapecerica da Serra, no valor de 0,03 , indica que a quantidade de homicídios ocorridas no ano de 2012 é muito próximo da média da série histórica, já o valor de 9,53 do Rio de Janeiro está distante da média. Logo a probabilidade do resultado obtido pelo Rio de Janeiro ser fruto do acaso é menor do que o resultado obtido por Itapecerica da Serra.

Os Municípios de Roteiro e Rodrigues Alves apresentaram as mesmas NE(média), no entanto no ano 2012 no primeiro ocorreu apenas um homicídio, enquanto no mesmo ano no outro, ocorreram dois homicídios. O fato é que para os dois Municípios a quantidade de homicídios ocorridos coincidiu com as médias das séries temporais, para uma distribuição padronizada a média representa o ponto com maior concentração de eventos e portanto com os eventos de maior probabilidade de ocorrência.

Uma observação importante, que compromete o modelo proposto é a necessidade de $\lambda$ ser maior que zero. Dos 5.565 municípios relacionados no Mapa da Violência, (WAISELFISZ, 2014), os valores das estatísticas das séries temporais compreendidas pelos anos de 2008 até 2011, foram assim distribuídos: 1.789 municípios apresentaram a mediana igual zero, para 861 município a média foi igual a zero e 861 municípios a média e a mediana foram iguais a zero. Para um montante de 3.776 a média e a mediana puderam ser calculadas. As duas estatísticas zeradas é um indicativo de que a série temporal está zerada, não ocorreu homicídio no município, nesse caso não há como aplicar o modelo vez que o desvio padrão também será zerado.

Vale ainda observar que os dados utilizados são provenientes de uma série anual, apenas os totais referentes aos anos de 2008, 2009, 2010 e 2011 
foram utilizados para uma comparação com o total do ano de 2012. Para avaliaçôes mensais os dados disponíveis na série teriam que ser mensais, um total de 48 registros $(48=4 \times 12)$. Para uma distribuição de POISSON teórica temos que para o conjunto de dados a média deve ser igual a variância e o parâmetro $\lambda$ deve ser igual a média. Em situações reais os valores da média, da variância e de $\lambda$ irão tender a se aproximarem a medida que se aumenta a quantidade de observações. As séries temporais trabalhadas permitiram conjuntos de dados com apenas quatro observações, com uma quantidade tão pequena de dados é evidente que se trabalha com significativa margem de erro nas estimações dos parâmetros $\lambda$. Também percebemos que em todas as séries há uma grande distância separando os valores das médias das variâncias. No entanto esses problemas serão eliminados com a utilização de amostras maiores.

\section{Consideraçóes Parciais}

O procedimento proposto para avaliar a eficiência de resultados em segurança pública sobre um determinado território comparando o território avaliado com outros buscou a construção de um modelo que possibilitasse levar em consideração as diferenças entre os terriórios. Não acreditamos que haja justiça em comparar territorios historicamente pacíficos com outros historicamente violentos considerando os dados nas suas formas brutas. Essa comparação só será correta se os resultados forem padronizados.

No modelo proposto a padronização é feita considerando como médida o valor do desvio padrão de cada grupo de dados e a distância da médida em relação a média, que aplicado ao problema em estudo define que quanto mais distante o valor avaliado estiver da média, mais rara a problabilidade de ocorrência do valor e menos provável que ele seja decorrente do acaso.

Uma questão em aberto é qual o tamanho ideal da série temporal tomada para o cálculo do parametro lambda. É uma indagação que depende de avaliações específicas, que devem considerar, a disponibilidade dos dados e as variações sociais, econômicas, políticas e demográficas ocorridas nos territórios, entre outras variáveis. O lapso de 60 meses, ou 60 observações, adotado nesta pesquisa partiu da premissa que em cinco anos as variações no território seriam pequenas. $\mathrm{O}$ fato é que no Brasil atual, considerando que a criminalidade e a violência parecem estar em crescimento exponencial, as séries temporais podem exigir estudos específicos quanto as tendências, sazonalidades e ruídos. Um corte transversal muito longo levara para os cálculos 
valores que já foram ultrapassados historicamente e que em decorrência da tendência venham a não se repetir. Já um intervalo diminuto poderá ter o efeito de desprezar o histórico do território indo contra um dos objetivos do estudo. Um corte reduzido também se distanciará das restrições do Teorema do Limite Central e induzirá a erros maiores.

Vale observar que resultados em segurança pública podem ser frutos de diversos fatores atuando em conjunto. Uma política pública de educação e outra política pública em saúde podem, hipoteticamente tratando, influenciar mais nos resultados de um indicador de segurança pública do que em políticas específicas sobre o assunto. Mas a dicussão desse tema foge ao escopo deste trabalho.

A conclusão final é que o uso de padronização de escores é um metodo eficiente para identificar qual dos territórios apresentou um resultado relativamente melhor para uma avaliação da segurança pública aplicadas e permite uma mensuração da eficiência e da eficácia dos diferentes sistemas de gestão aplicados.

Luís Henrique Costa Ferreira

Mestre em Segurança Pública, Justiça e Cidadania. Possui
Graduação em Engenharia Civil pela Universidade Católica
do Salvador (1986), Bacharelado Em Direito Pela Universidade
Católica do Salvador (1994) e graduação em Licenciatura Em
Matemática pela Universidade Católica do Salvador (1986).
Atualmente É Delegado de Policia Civil Estado da Bahia..
E-mail: luishcferreira@globo.com

\title{
EVALUATING RESULTS OF PUBLIC SAFETY ACTIONS
}

\begin{abstract}
The usual in evaluating the results of public security actions is the behavior of the chosen variables are analyzed in terms of clusters represented by territories. Although easy application and interpretation always watched with suspicion that system. I disagree in comparing territories without considering the social, historical and economic thereof. This paper presents a model for comparing the actions against violence developed in the various territories using standard measures. The goal is to discover, for medium and deviations different patterns for a given criminal variable, which territory has a relatively better result. And like all territories can be classified with each other?
\end{abstract}

KEYwORDS: Crime. Time Series. Probability Analysis. 


\title{
Evaluación de Acciones de Seguridad Pública RESULTADOS
}

\begin{abstract}
RESUMEN
Es habitual en las evaluaciones de los resultados de las acciones de seguridad pública que se tomen mediciones en el comportamiento de las variables elegidas como indicadores para el análisis de los conglomerados representados por territorios. Los datos son analizados en relación al territorio para evaluar si existía o no un aumento en la frecuencia de la variable estudiada. Los resultados se evaluaron comparando los datos obtenidos para diferentes territorios. Aunque sea de fácil aplicación e interpretación, siempre he mirado con recelo este sistema, ya que no estoy de acuerdo en comparar territorios sin tener en cuenta su contexto social, histórico y económico. Es imperativo que se tengan en cuenta las características individuales de cada territorio. En este trabajo se presenta un modelo para la comparación de las acciones contra la violencia desarrollada en diferentes territorios que tiene en cuenta el comportamiento histórico de la variable de indicador elegido y permita evaluaciones de desempeño y competencia consistentes. El modelo propuesto se ha desarrollado para responder, teniendo en cuenta las características individuales de los territorios, cuál ha presentado un mejor resultado para la variable indicador penal. Es decir, indicar medias y desvios patrones diferentes en un mismo intervalo de tiempo, teniendo en cuenta una determinada variable Criminal, cual de los territorios presentó un resultado relativamente mejor. Y como todos los territorios se pueden clasificar entre ellos.
\end{abstract}

Palabras Clave: Crime. series de tiempo. Probabilidad. Análisis.

\section{REFERÊNCIAS}

BEATO, C. C. (11 de 6 de 2015). Ministério Público do Estado da

Bahia. Fonte: Ministério Público do Estado da Bahia: http://www. mpba.mp.br/atuacao/ceosp/artigos/claudio_beato_pol_pub_ seguranca_equidade_eficiencia_acco.pdf

BECKER, H. S. (2007). Segredos e turques da pesquisa. (M. L. Borges, Trad.) Rio de Janeiro, RJ, Brasil: Zahar.

CLAVE, J. T., BENSON, P. G., \& SINCICH, T. (2009). Estatística para administradores. São Paulo: Pearson Prentice.

Escritório das Nações Unidas sobre Drogas e Crime (UNODC) . (11 de 6 de 2015). UNODC . Fonte: UNODC - United Nations Office on Drugs an Crime: http://www.unodc.org/lpo-brazil/ 
pt/frontpage/2009/04/24-indices-globais-de-homicidios-estaoestaveis-ou-em-queda-diz-novo-relatorio-do-unodc.html

GUJARATI, D. N., \& DAWN, C. P. (2011). Econometria Básica. Porto Alegre: AMGH.

LAPPONI, J. C. (2005). Estatística usando Excel. Rio de Janeiro: Elsevier.

LARSON, R. (2010). Estatística aplicada. São Paulo: èarson Prentice Hall.

LEVIN, J., \& FOX, J. A. (2004). Estatística para ciências humanas. São Paulo: Prentice Hall.

LOESCH, C. (2012). Probabilidade e estatística. Rio de Janeiro: LTC.

RUMSEY, D. (2012). Estatística para leigos. Rio de Janeiro: Alta Books.

SCHMULLER, J. (2010). Análise estatística com Excel. Rio de Janeiro: Alta Books.

SCURO NETO, P. (2004). Sociologia ativa e didática. São Paulo: Saraiva.

WAISELFISZ, J. J. (2014). Mapa da Violência. Fonte: Mapa da Violência: http://www.mapadaviolencia.org.br/

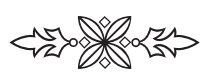

